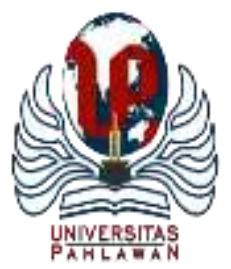

Edukatif : Jurnal Ilmu Pendidikan Volume 3 Nomor 6 Tahun 2021 Halm 4757 - 4762

EDUKATIF: JURNAL ILMU PENDIDIKAN

Research \& Learning in Education

https://edukatif.org/index.php/edukatif/index

\title{
Hasil Cowl Drapery menggunakan Teknik Draping
}

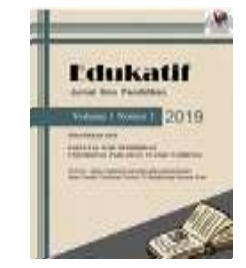

\author{
Yasnidawati $^{1 凶}$, Ela Nurlita ${ }^{2}$ \\ Universitas Negeri Padang, Indonesia, ${ }^{2}$ \\ E-mail : yasnidawati587@gmail.com
}

\begin{abstract}
Abstrak
Penelitian ini bertujuan untuk mendeskripsikan hasil cowl drapery menggunakan Teknik Draping. Jenis penelitian yang digunakan adalah penelitian terapan. Objek penelitian yaitu cowl drapery menggunakan teknik draping. Instrumen penelitian memakai format penilaian dengan Skala Likert. Penilaian dilakukan oleh 3 orang panelis yaitu dosen yang ahli dalam bidang busana, dengan cara fitting. Teknik analisis data yang digunakan adalah deskriptif kuatitatif dan analisis inferensial. Hasil cowl drapery menggunakan Teknik Draping menunjukkan hasil cowl drapery menggunakan teknik draping didapatkan hasil penilaian dengan nilai persentase sebesar 80.21 \% dikategorikan sesuai. Berdasarkan uji t didapatkan hasil rata-rata penilaian yang signifikan antara hasil jadi cowl drapery menggunakan teknik draping dengan taraf signifikansi sebesar 0.05 .
\end{abstract}

Kata kunci: Cowl drapery; draping

Abstract

This study aims to describe the results of cowl drapery using the draping technique. The type of research used is applied research. The object of research is cowl drapery using draping technique. The research instrument uses an assessment format with a Likert Scale. The assessment is carried out by 3 panelists, namely lecturers who are experts in the field of clothing, by fitting. The data analysis technique used is quantitative descriptive and inferential analysis. The results of the cowl drapery using the draping technique show that the results of the cowl drapery using the draping technique obtained an assessment result with a percentage value of $80.21 \%$ categorized as appropriate. Based on the t-test, it was found that the average results were significant between the results of cowl drapery using the draping technique with a significance level of 0.05.

Keywords: Cowl drapery; draping

Copyright (c) 2021 Yasnidawati, Ela Nurlita

$\triangle$ Corresponding author

Email : yasnidawati587@gmail.com

DOI : https://doi.org/10.31004/edukatif.v3i6.1487

ISSN 2656-8063 (Media Cetak)

ISSN 2656-8071 (Media Online) 


\section{PENDAHULUAN}

Berbicara mengenai model busana, drapery tentu tidak asing bagi penyuka fashion terbukti banyak para designer-designer yang berlomba mengeluarkan bermacam-macam model busana khas mereka untuk menarik minat para konsumen, salah satunya adalah model busana dengan hiasan drapery. Pengertian drapery menurut (Christine, 2015) adalah: "hiasan pada pakaian, berupa gelombang-gelombang kecil atau lipit-lipit yang dibuat dari kain yang arahnya serong". Drapery memiliki beberapa tipe, salah satunya adalah Cowl drapery, menurut (Joseph, 2008), (Arifah et al., 2009) "Cowl adalah lipatan kain yang dibuat dengan kain yang jatuh pada kedalaman yang diinginkan dari ujung pembiasan segitiga atau menyerong. Kualitas cowl yang baik jika tepat menggunakan arah menyerong dan kain yang digunakan lembut seperti crepe, sutra, gauze, rayon, satin, sifon dan rajutan tertentu. Kedalaman cowl tergantung pada jumlah kedalaman yang diambil pada arah yang melebar. Semakin rendah kedalaman cowl maka akan semakin besar jumlah axcess yang dibutuhkan, yaitu dengan sebuah penerapan manipulasi lipatan atau dengan dart". Cowl neckline adalah model drapery yang terdiri dari lipatan kain yang jatuh dari leher dan memberikan efek draping pada bagian depan busana. Dengan model cowl neckline, sebuah busana tidak perlu diberikan hiasan pada bagian depan, karena dengan model ini sudah memberikan efek yang memperindah busana.

Membuat busana dengan model drapery cowl neckline dapat memilih bahan apapun, yang penting bahan tersebut dapat jatuh dan membentuk garis-garis lipatan atau gelombang secara maksimal. Cowl neckline drapery dapat dibuat dengan teknik draping maupun teknik kontruksi, menurut Tortora \& Markel (1996) dalam Kaya \& Cagdas (2014), (Yulianti, 1993), (Tortora, 2019), (Subandi, 2019) (Agustini et al., 2019), "draping adalah fleksibitas kain pada saat digantung pada posisi yang berbeda, untuk diubah ke dalam bentuk yang anggun. Teknik draping memiliki kemungkinan untuk lebih leluasa memberi variasi yang diinginkan sehingga metode ini lebih kreatif'. Sedangkan teknik kontruksi menurut (Pratiwi, 2014) "Teknik Konstruksi adalah sketsa bayangan dari bentuk badan yang digambarkan untuk mengilustrasikan secara visual maksud dari garis yang dalam penggambarannya menggunakan ukuran badan yang telah dicatat pada daftar ukuran".

Pembuatan cowl drapery yang baik harus memperhatikan beberapa indikator, meliputi keluesan gelombang drapery, kerataan gelombang drapery, jarak tiap gelombang drapery dan ketepatan letak drapery sesuai desain (Jaffe, 2005), (Lindqvist, 2013),(Lestari, 2014), (Nobel, 2019), (Raleigh, 2004). Teknik draping merupakan teknik pembuatan busana yang mengandalkan lipatan, kerutan, tekukan, dan sebagainya tanpa kain harus dijahit terlebih dahulu. Teknik ini sering digunakan oleh perancang busana yang menggunakan penyelesaian tingkat tinggi. Berdasarkan permasalahan di atas, maka untuk lebih jelasnya perlu dilakukan penelitian dengan judul "Perbedaan Hasil Cowl Drapery Menggunakan Teknik Draping."

\section{METODE PENELITIAN}

Berdasarkan tujuan penelitian yang telah dikemukakan, maka jenis penelitian ini merupakan penelitian terapan (Sugiyono, 2016). Penelitian terapan adalah yang dimaksudkan untuk menerapkan, menguji, dan mengevaluasi kemampuan suatu teori yang ditetapkan dalam memecahkan masalah praktis. Objek penelitian ini adalah hasil cowl drapery menggunakan Teknik Draping yang diuji cobakan pada dressform. Lokasi penelitian ini dilakukan di Jurusan Ilmu Kesejahteraan Keluarga Fakultas Pariwisata Perhotelan. Variabel independent (bebas) dan variable dependent (terikat) pada penelitian ini antara lain : Teknik draping $(\mathrm{X})$, hasil jadi cowl drapery $(\mathrm{Y})$ sebagai variabel terikat. Instrumen yang digunakan dalam penelitian ini adalah kuisioner atau angket. Skala yang digunakan adalah skala likerts yang berisikan 4 pilihan jawaban, yaitu: Sangat Setuju (SS) dengan skor 4, Setuju (S) dengan skor 3, Tidak Setuju (TS) dengan skor 2, Sangat Tidak Setuju (STS) dengan skor 1. Pelaksanaan penilaian dilaksanakan pada waktu pengepasan busana pada model. Diamati dan dievaluasi dibawah bimbingan 3 dosen penilai (panelis) yang ahli dalam bidang busana (panel 
terbatas). Uji coba instrumen menggunakan bantuan program Microsoft Excel.

Teknik analisis data yang digunakan antara lain: 1) Analisis deskriptif dengan pendekatan kuantitatif meliputi modus, median dan persentase. 2) Uji prasyarat analisis yaitu dengan uji normalitas dan homogenitas. 3) Pengujian hipotesis, Pengujian Hipotesis untuk mengetahui ada tidaknya hubungan antar variabel menggunakan independent $t$-test.

\section{HASIL PENELITIAN DAN PEMBAHASAN}

Hasil penelitian ini sesuai dengan teknik analisis data yang digunakan antara lain:

1. Analisis deskriptif hasil cowl drapery menggunakan teknik draping

Tabel 1. Analisis Deskriptif Hasil Cowl Drapery Menggunakan Teknik Draping

\begin{tabular}{lccc}
\hline & Panelis I & Panelis II & Panelis III \\
\hline Mean & 3.25 & 3.25 & 3.13 \\
\hline Median & 3 & 3 & 3 \\
\hline Modus & 3 & 3 & 3 \\
\hline Presentase & $81.25 \%$ & $81.25 \%$ & $78.13 \%$ \\
\hline \multicolumn{4}{l}{} \\
\hline
\end{tabular}

Dari hasil uji analisis deskriptif melalui microsof excel di atas, mean/ratarata penilaian Panelis I dan Panelis II adalah sebesar 3.25, ini menunjukkan penilaian antara sesuai dengan sangat sesuai namun lebih mendekati penilaian sesuai untuk rata-rata penilaian oleh panelis III adalah sebesar 3.13, yang menunjukkan penilaian sesuai. Pada hasil cowl drapery menggunakan teknik draping, jumlah penilaian ketiga panelis adalah sebesar $80.21 \%$ dengan modus/mode/ penilaian dari ketiga panelis adalah sesuai dengan kecenderungan tengahnya juga sesuai.

Tabel 2. Presentase tiap Indikator Hasil Cowl Drapery Menggunakan Teknik Draping

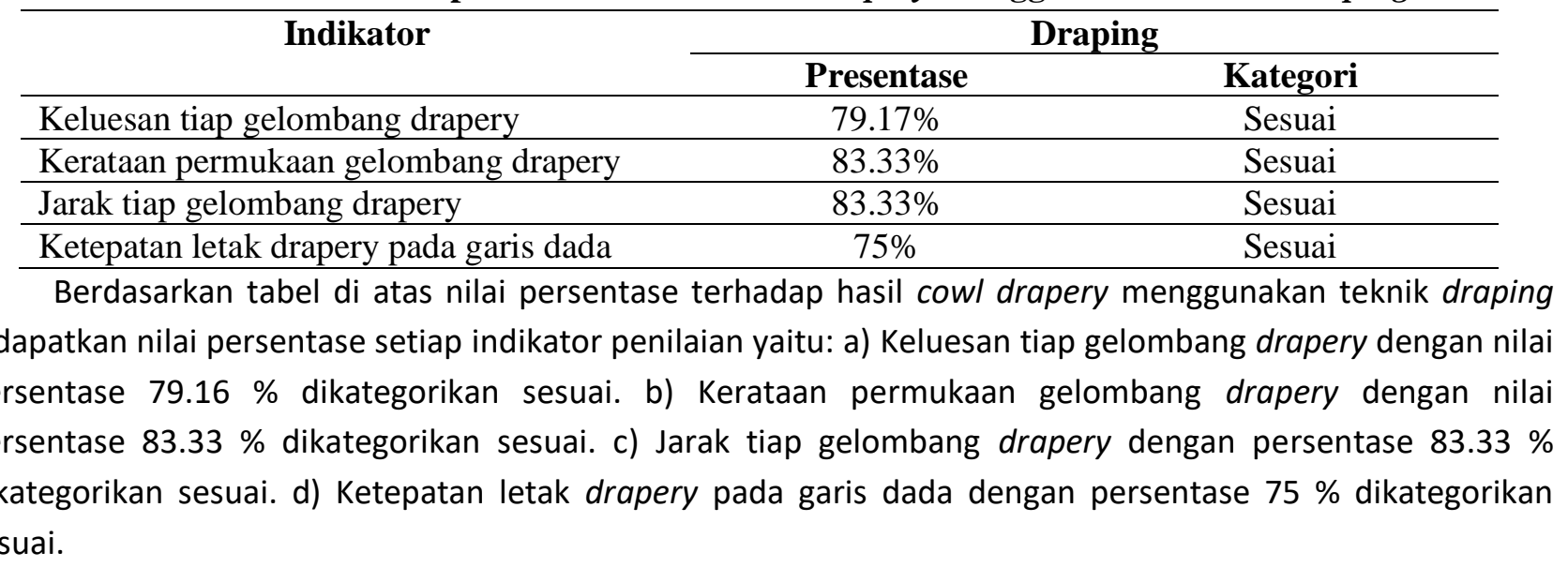

\section{Uji prasyarat analisis yaitu dengan uji normalitas dan homogenitas.}

a. Normalitas

Adapun analisis yang digunakan untuk uji asumsi normalitas ini adalah uji K-S (Kolmogorof-Smirnov). Pada uji K-S hasil D_hitung akan dibandingkan dengan D_tabel dengan taraf signifikan sebesar 0.05. terima Ho jika D_hitung < D_tabel dengan keputusan Terima Ho yang berarti data Berdistribusi Normal. Berikut adalah hasil pengujian normalitas menggunakan analisis K-S secara manual dengan bantuan microsoft excel.

Tabel 3. Uji Normalitas

D_hitung $\quad$ D_tabel $\quad$ Kriteria $\quad$ Keputusan $\quad$ Kesimpulan


4760 Hasil Cowl Drapery menggunakan Teknik Draping - Yasnidawati, Ela Nurlita

DOI: https://doi.org/10.31004/edukatif.v3i6.1487

\begin{tabular}{cccccc}
\hline Panelis I & 0.4554 & 0.4570 & D_hit $<$ D_tabel & Terima Ho & $\begin{array}{c}\text { Data Berdistribusi } \\
\text { Nomal }\end{array}$ \\
\hline Panelis II & 0.4554 & 0.4570 & D_hit $<$ D_tabel & Terima Ho & $\begin{array}{c}\text { Data Berdistribusi } \\
\text { Nomal }\end{array}$ \\
\hline Panelis III & 0.3254 & 0.4570 & D_hit $<$ D_tabel & Terima Ho & $\begin{array}{c}\text { Data Berdistribusi } \\
\text { Nomal }\end{array}$ \\
\hline
\end{tabular}

b. Homogenitas

Uji homogenitas (kesamaan varians) dapat dilakukan dengan menggunakan F-Test Two_Sample for Varians pada Microsoft Excel, sehingga didapat:

Tabel 4. Uji Homogenitas

\begin{tabular}{cccccc}
\hline & f_hitung & f_tabel & Kriteria & Keputusan & Kesimpulan \\
\hline Panelis I & 1 & 3.7870 & F_hit $<$ F_tabel & Terima Ho & Data Homogen \\
\hline Panelis II & 1.3333 & 3.7870 & F_hit $<$ F_tabel & Terima Ho & Data Homogen \\
\hline Panelis III & 1.3910 & 3.7870 & F_hit $<$ F_tabel & Terima Ho & Data Homogen \\
\hline
\end{tabular}

Dapat disimpulkan bahwa data Panelis I, Panelis II, dan Panelis III pada hasil cowl drapery menggunakan teknik draping adalah homogen atau memiliki kesamaan varians atau tidak ada perbedaan varians antar kelompok responden hasil cowl drapery menggunakan teknik draping dengan taraf signifikansi sebesar 0.05 .

3. Pengujian hipotesis, Pengujian Hipotesis untuk mengetahui ada tidaknya hubungan antar variabel menggunakan independent $t$-test.

Tabel 5. Uji T Hasil Cowl Drapery Menggunakan Teknik Draping

\begin{tabular}{cccccc}
\hline & T_hitung & T_tabel & Kriteria & Keputusan & Kesimpulan \\
\hline X\&Y & 1.7838 & 2.4469 & T_hit $<$ T_tabel & Terima Ho & $\begin{array}{c}\text { Data Memiliki } \\
\text { Kesamaan Rataan }\end{array}$ \\
\hline
\end{tabular}

Berdasarkan uji $\mathrm{t}$ diatas dapat disimpulkan terdapat perbedaan yang signifikan terhadap hasil cowl drapery menggunakan teknik draping dilihat dari 4 indikator penilaian (Keluesan tiap gelombang drapery, kerataan permukaan gelombang drapery, jarak tiap gelombang drapery dan ketepatan letak drapery pada garis dada) (Yasnidawati, 2012). Berdasarkan hasil analisis terhadap hasil cowl drapery menggunakan teknik draping didapatkan jumlah keseluruhan nilai persentase panelis sebesar $80.21 \%$ dikategorikan Sesuai. Artinya pada indikator keluesan tiap gelombang drapery memiliki kategori tingkat pencapaian $79.17 \%$ dikategorikan Sesuai, didapatkan hasil gelombang drapery yang melangsai dan jatuh menjuntai. Hal ini sesuai dengan yang dikatakan (Agustin, 2014) Rok drapery adalah lipit-lipit kerut yang mempunyai titik-titik pusat dari mana lipit-lipit atau kerut itu berpangkal dan jatuhnya bebas berdasarkan melangsainya suatu bahan drapery merupakan jatuhnya suatu bahan tekstil pada busana berupa kerutan atau lipit - lipit kecil yang berpusat pada tempat tertentu, karena bahannya melangsai, (lembut dan jatuhnya seperti ayunan)". Dan menurut (Aisyah, 2019), (Sugiyono, 2016) drapery merupakan jatuhnya gelombang atau lipatan mulai dari yang halus lembut, sampai membentuk gelombang yang besar jatuh menjuntai pada busana. Kerataan permukaan gelombang drapery memiliki kategori tingkat pencapaian $83.33 \%$ dikategorikan Sesuai. Artinya setiap lengkungan gelombang drapery teratur dan tidak teratarik. Jarak tiap gelombang drapery memiliki kategori tingkat pencapaian $83.33 \%$ dikategorikan Sesuai. Artinya susunan jarak gelombang drapery terlihat indah dan kedalaman setiap gelombangnya terlihat bagus sesuai dengan desain yang dibuat. Ketepatan letak drapery pada garis dada memiliki kategori tingkat pencapaian $75 \%$ dikategorikan Sesuai. Artinya drapery terletak 
4761 Hasil Cowl Drapery menggunakan Teknik Draping - Yasnidawati, Ela Nurlita

DOI: https://doi.org/10.31004/edukatif.v3i6.1487

tepat di atas garis dada dan terlihat indah sesuai dengan desain (Yasnidawati, 2007), (Sawitri, 1997), (Amaden, 2011), (Fakhrunnisa, 2016). Dari uraian di atas, hasil yang lebih baik dalam pembuatan cowl drapery adalah dengan menggunakan teknik draping, hal ini sejalan dengan penelitian yang dilakukan sebelumnya oleh Mia Yuliani Tahun 2018 yang berjudul Hasil Pembuatan Rok Drapery Menggunakan Pola Draping Dan Pola Konstruksi Berbasis Komputer, dengan hasil penelitian yang dilakukan dengan adanya tiga pengulangan pembuatan produk termasuk dalam kategori baik, dengan nilai rata-rata pada pengulangan pertama sebesar 40, pengulangan kedua sebesar 40 dan pengulangan ketiga sebesar 41,3.

\section{KESIMPULAN}

Berdasarkan permasalahan, pertanyaan penelitian dan pembahasan yang telah dilakukan, maka dapat disimpulkan sebagai berikut: Hasil jadi cowl drapery menggunakan teknik draping memiliki hasil baik. Dapat dilihat dari persentase penilaiannya lebih tinggi

\section{DAFTAR PUSTAKA}

Agustin, R. (2014). Pengaruh Ketebalan Kain Duchesse Terhadap Hasil Jadi Rok Draperi Ria Agustin Suhartiningsih Abstrak. 03, 1-5.

Agustini, A., Sudirtha, I. G., \& Angendari, M. D. (2019). Pengembangan Busana Pesta Malam Dengan Sumber Ide Dari Mitologi Kerajaan Yunani. Jurnal Bosaparis: Pendidikan Kesejahteraan Keluarga, 9(3), 222. Https://Doi.Org/10.23887/Jjpkk.V9i3.22152

Aisyah, S. (2019). Analisis Perbedaan Karakteristik Bahan Tekstil Pada Pembuatan Busana Model Draping Cowl Neckline. Prosiding Seminar Nasional Lembaga Penelitian Universitas Negeri Makassar, 391395.

Amaden, C. \& C. (2011). The Art Of Fashion Draping. America Bloomsbury.

Arifah, A., Zulbahri, L., \& Riyanto. (2009). Modul Dasar Busana. Universitas Pendidikan Indonesia, 1, 66. Https://Docplayer.Info/30943299-Modul-Dasar-Busana-Oleh-Prof-Dr-Arifah-A-Riyanto-M-Pd-DraLiunir-Zulbahri-M-Pd.Html

Christine. (2015). Busana Eksklusif Model Draperi. Gramedia Pustaka Utama.

Fakhrunnisa, M. (2016). Gaya Busana Sebagai Media Pembentukkan Identitas Musik White Shoes And The Couples Company Oleh: Acta.

Jaffe, H. (2005). Draping For Fashion Design . Fourth Edition.New Jersey: Pearson Education, Inc Jerde, Judith. Encyclopedia Of Textiles.

Joseph, H. (2008). Helen Joseph Amstrong. 1995. Pattern Making For Fashion Design . Lose Angeles Trade Technical College: The Fashion Center (T. F. Center (Ed.)).

Lestari, S. B. (2014). Fashion Sebagai Komunikasi Identitas Sosial Di Kalangan Mahasiswa. Ragam Jurnal Pengembangan Humaniora, 14(3), 225-238.

Lindqvist, R. (2013). On The Logic Of Pattern Cutting Foundational Cuts And Approximations Of The Body. $3,2013$.

Nobel, A. A. (2019). Perancangan Busana Ready To Wear Wanita Dengan Gaya Japanese Streetstyle Menggunakan Metode Zero Waste. Jurnal Rupa, 1605154002(1), 2250-2257.

Pratiwi. (2014). Pola Dasar Dan Pecah Pola Busana. Kanisius.

Raleigh, E. (2004). Busana Muslim Dan Kebudayaan Populer Di Indonesia: Pengaruh Dan Persepsi. Busana Muslim Dan Kebudayaan Populer Di Indonesia : Pengaruh Dan Persepsi, 14.

Sawitri, S. (1997). Tailoring. Ikp. 
4762 Hasil Cowl Drapery menggunakan Teknik Draping - Yasnidawati, Ela Nurlita DOI: https://doi.org/10.31004/edukatif.v3i6.1487

Subandi, P. E. S. (2019). Upt Perpustakaan Isi Yogyakarta Upt Perpustakaan Isi Yogyakarta. Computers In Human Behavior, 63(May), 9-57.

Sugiyono. (2016). Metode Penelitian Kuantitatif, Kualitatif Dan R \& D. Alfabeta.

Tortora, G. J. (2019). Principles Of Anatamy And Physiology. Printed In The United States Of America. Yasnidawati. (2007). Busana Kerja. Unp Press.

Yasnidawati. (2012). Model Tailoring. Unp Press.

Yulianti, N. A. (1993). Teknologi Busana. Ikip. 